\title{
Evaluasi Kinerja Tampungan Waduk Selorejo Menggunakan Perangkat Lunak HEC-HMS
}

\author{
Performance Evaluation of Selorejo Reservoir Using HEC-HMS Software
}

\author{
Christian Cahyono 1,*, Dhanny Susetyo ${ }^{2}$, Henny Herawati ${ }^{3}$, Juliastuti 4 \\ 1,2,4 Fakultas Teknik Universitas Bina Nusantara, Jl. Kyai H. Syahdan No.9, Jakarta Barat 11480, DKI Jakarta, Indonesia \\ ${ }^{3}$ Program Studi Teknik Sipil Universitas Tanjungpura, Jl. Prof. Dr. H. Hadari Nawawi, Pontianak, Indonesia
}

\author{
* Penulis korespondensi : Christian.cahyono@binus.ac.id \\ Tel.: +62-81-295-503-402 \\ Diterima: 6 April 2021; Direvisi: 25 April 2021; Disetujui: 26 April 2021. \\ DOI: 10.25299/saintis.2021.vol21(01).6695
}

\section{Abstrak}

Permasalahan banjir merupakan permasalahan pengelolaan air yang sering terjadi di Indonesia. Untuk mengatasi permasalahan tersebut dibuat sebuah struktur yaitu waduk yang berfungsi sebagai pengendali banjir. Namun seiring waktu tampungan waduk akan semakin menurun akibat adanya akumulasi sedimen yang terbawa oleh air sungai yang masuk ke dalam waduk dan mengendap. Sehingga diperlukan evaluasi kinerja tampungan waduk tersebut, Permasalahan ini juga dialami oleh Waduk Selorejo yang terletak di Kabupaten Malang. Untuk melakukan evaluasi kinerja tampungan waduk digunakan bantuan perangkat lunak HEC-HMS yang dapat mensimulasikan debit banjir yang masuk beserta elevasi tampungan waduk. Berdasarkan hasil analisis tampungan Waduk Selorejo mampu untuk mengendalikan banjir periode ulang desain awal nya yaitu periode ulang 1000 tahun. Selain itu Waduk Selorejo juga mampu menampung debit banjir Probable Maximum Flood (PMF) apabila muka air awal waduk diturunkan sampai elevasi +605 m.

Kata Kunci: Banjir, HEC-HMS, Periode Ulang, Tampungan, Waduk

\begin{abstract}
Flood problem is a water management problem that often occurs in Indonesia. To overcome this problem, a structure is created, namely DAM that functions as a flood controller. However, over time the reservoir storage will decrease due to the accumulation of sediment carried by river water that enters the reservoir. So it is necessary to evaluate the performance of the Rervoir storage. This problem is also experienced by the Selorejo DAM which is located in Malang Regency. To evaluate the performance of the reservoir storage, the help of HECHMS software is used which can simulate the incoming flood discharge along with the elevation of the reservoir. Based on the analysis, the Selorejo DAM is able to control the flood of its initial design period which is the 1000-year return period. In addition, the Selorejo Reservoir is also able to accommodate the Probable Maximum Flood (PMF) flood discharge if the initial water level of the reservoir is lowered to an elevation of $+605 \mathrm{~m}$.
\end{abstract}

Keywords: DAM, Flood, HEC-HMS, , Reservoir, Return Period

\section{PENDAHULUAN}

Air adalah salah satu sumber daya yang dibutuhkan oleh semua makhluk hidup bahkan lingkungan. Melihat fakta ini, pengelolaan terhadap sumber daya air menjadi penting. Pengelolaan sumber daya air yang baik harus dapat mengatasi permasalahan air yang selama ini dialami yaitu permasalahan banjir. Salah satu cara dalam mengatasi permasalahan banjir yaitu dapat membuat sebuah waduk. Waduk merupakan struktur masif berupa kolam yang berguna untuk menampung air yang masuk. Salah satu fungsi waduk adalah pengendalian banjir. Dalam operasi nya, waduk akan menampung air yang masuk dari sungai dimana air tersebut akan mengangkut pula sedimen sehingga kapasitas waduk akan berkurang seiring waktu akibat adanya deposit sedimen yang di bawah oleh air dri sungai yang masuk ke dalam waduk. Oleh karena adanya permasalahan ini keamanan waduk perlu di evaluasi dalam kala waktu tertentu apakah waduk masih mampu untuk menampung debit banjir dari sungai berdasarkan desain awalnya. Pada penelitian ini Waduk Selorejo menjadi lokasi studi dimana data menunjukkan terdapat penurunan cukup tinggi volume tampungan waduk tahun 2010 ke tahun 2017. Oleh karena adanya permasalahan ini penelitian dilakukan untuk melihat apakah tampungan waduk pada tahun 2017 masih mampu untuk mengakomodasi debit banjir kala ulang desain awal dari Waduk Selorejo.

Dalam penelitian ini digunakan perangkat lunak HEC-HMS. Perangkat lunak ini membantu proses pemodelan Daerah Aliran Sungai (DAS) Selorejo untuk transformasi dari hujan periode ulang menjadi debit serta membantu proses penelusuran elevasi tampungan Waduk Selorejo ketika menerima debit banjir DAS Selorejo pada berbagai periode ulang. Selain itu apabila 
tampungan Waduk Selorejo tidak mampu menerima banjir periode ulang tertentu, HEC-HMS juga dapat membantu mensimulasikan berapa elevasi muka air waduk awal agar Waduk Selorejo mampu menampung banjir periode ulang tersebut. Tujuan penelitian ini adalah melakukan evaluasi secara hidrologi kinerja tampungan Waduk Selorejo. Kinerja yang dimaksud adalah apakah Waduk Selorejo masih mampu menampung banjir berbagai periode ulang sesuai dengan desain awal dari Waduk Selorejo dengan memanfaatkan perangkat lunak HEC-HMS.

Berdasarkan studi literatur yang dilakukan, evaluasi tampungan waduk sudah banyak dilakukan baik di Indonesia maupun di luar. Sebagai contoh beberapa DAS di Indonesia seperti Waduk Mundingan di [1], Bendungan Way Yori di Ambon [2], Waduk Cengklik di Boyolali [3], dan Setu Tarisi di Majalengka [4]. Analisis debit banjir untuk evaluasi tampungan waduk yang dilakukan di Indonesia masih berbasis perhitungan hidrograf satuan maupun manual secara excel. Kedua metode ini masih kurang baik karena hidrograf satuan yang dibuat berlaku untuk satu DAS padahal keadaan dalam satu DAS tidaklah homogen sehingga perlu dilakukan pemodelan yang lebih detil. Disini peran dari HEC-HMS menjadi terlihat dimana HEC-HMS mampu memodelkan DAS dengan lebih detil dengan membagi per subDAS dan mampu memodelkan kondisi fisik masing-masing subDAS sehingga menghasilkan pemodelan yang lebih baik. Analisis debit banjir untuk evaluasi tampungan waduk yang dilakukan di luar sudah memanfaatkan perangkat lunak HEC-HMS ini sebagai contoh Mae Sruai DAM di Thailand [5] dan Wadi Byash DAM di Arab Saudi [6]

Berdasarkan penemuan ini, analisis yang dilakukan ini memanfaatkan perangkat luncak HECHMS agar pemodelan yang dilakukan lebih detil dan menghasilkan hasil yang lebih merepresentasikan kondisi asli di lokasi studi.

\section{METODOLOGI}

Pada penelitian ini akan terdiri dari beberapa tahapan untuk mencapai tujuan utama penelitian yaitu mengevaluasi kemampuan tampungan Waduk Selorejo. Tahapan tersebut ditunjukkan oleh diagram alir pada Gambar 1. Pada proses pengumpulan data terdiri beberapa data yang digunakan yaitu data hujan baik berupa data hujan harian maupun data hujan jam-jam an, kondisi topografi DAS Selorejo, tata guna lahan, dan data teknik dari Waduk Selorejo. Data teknis tersebut berupa data tampungan tahun 2010 dan 2017, pelimpah Waduk Selorejo, debit keluaran tambahan Waduk Selorejo dan data pendukung lain. Sebelum proses evaluasi tampungan waduk, dilakukan proses kalibrasi model HEC-HMS DAS Selorejo untuk memperoleh beberapa parameter pemodelan agar debi banjir periode ulang yang dihasilkan oleh model memiliki nilai yang presisi. Setelah proses kalibrasi model sudah dinilai cukup baik, proses dilanjutkan dengan mengkalkulasi nilai debit banjir berbagai periode ulang pada DAS Selorejo serta dilakukan evaluasi tampungan waduk terhadap debit banjir periode ulang yang dihasilkan oleh model HEC-HMS. Apabila pada proses evaluasi diperoleh hasil tampungan waduk tidak mampu menerima debit banjir pada periode ulang tertentu dilakukan simulasi ulang dengan menurunkan elevasi awal muka air di waduk dan melihat hasilnya. Setelah proses analisis selesai ditarik kesimpulan dan penelitian ini dapat dikatakan selesai.

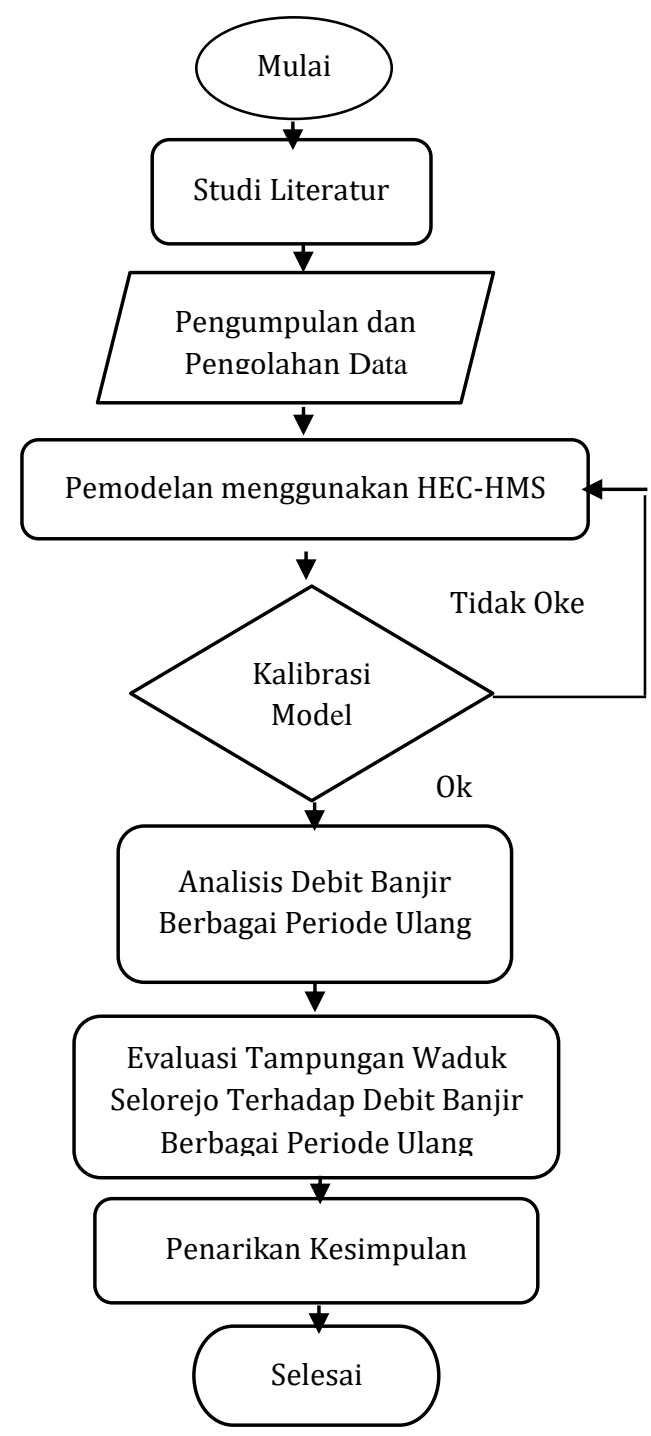

Gambar 1. Diagram Alir Penelitian

\section{HASIL DAN PEMBAHASAN}

Pada bagian ini akan dijelaskan secara lebih detil mengenai lokasi dari DAS dan Waduk Selorejo, proses pemodelan DAS Selorejo menggunakan HEC-HMS, input nilai parameter model, perhitungan curah hujan dan dan debit banjir pada berbagai periode ulang serta evaluasi tampungan dari Waduk Selorejo pada berbagai periode ulang. 


\section{Karakteristik Lokasi Studi}

Waduk Selorejo terletak di desa Pandansari, Kecamatan Ngantang, Kabupaten Malang. Lokasi bendungan berada pada K. Konto, anak sungai K. Brantas, tepat di bawah pertemuannya dengan $\mathrm{K}$. Kwayangan, + $50 \mathrm{~km}$ di sebelah Barat kota Malang, pada ketinggian $+650 \mathrm{~m}$ di atas permukaan laut. Pada saat proses konstruksi Waduk Selorejo dibangun untuk pengendalian banjir, pemberian air irigasi, pembangkit tenaga listrik, perikanan darat dan pariwisata. [7]. Berikut ditampilkan DAS Waduk Selorejo pada Gambar 2. DAS Waduk Selorejo memiliki luas sebesar 234,49 Km2. Pengukuran hujan pada DAS Waduk Selorejo terdapat pada 4 pos hujan yaitu Stasiun Jombok, Sekar, Selorejo, dan Pujon yang lokasi nya ditunjukkan oleh Gambar 3.

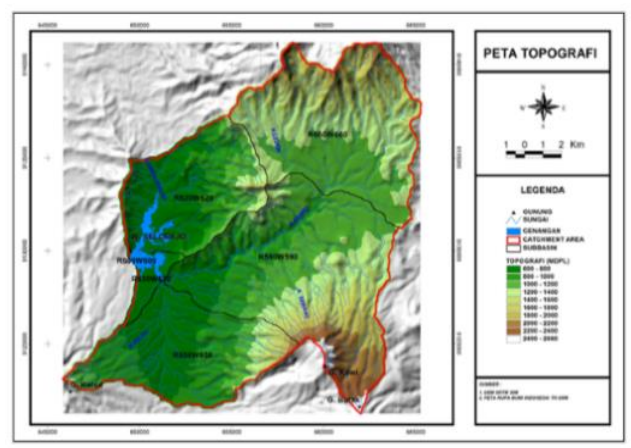

Gambar 2. DAS Waduk Selorejo

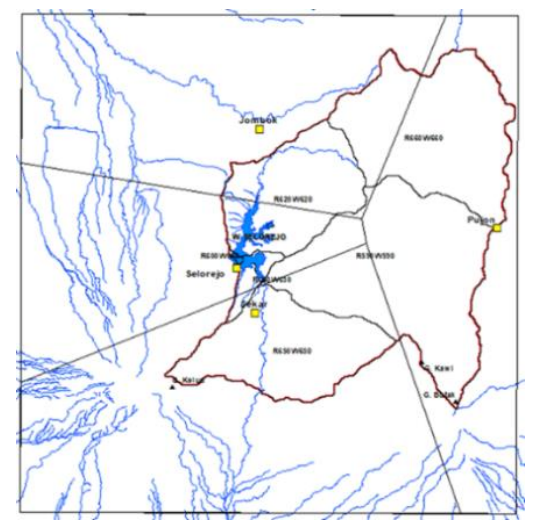

Gambar 3. Lokasi Pos Hujan DAS Waduk Selorejo dan Poligon Thiessen Pos Hujan

\section{Pemodelan dan Kalibrasi Model HEC-HMS}

Pada tahapan ini data DAS Waduk Selorejo yang telah diperoleh coba dimodelkan ke dalam perangkat lunak HEC-HMS. Dalam pemodelan HECHMS diperlukan untuk memodelkan secara fisik daerah studi yang ditinjau. Hal ini meliputi luas, panjang aliran dan kemiringan lahan dan saluran dari masing-masing subDAS tersebut. Selain komponen fisik, pemodelan HEC-HMS pada DAS Waduk Selorejo perlu dilakukan pada keadaan banjir dengan tujuan parameter hasil kalibrasi yang sudah tepat pada saat kejadian banjir dapat digunakan untuk memodelkan kejadian banjir pada berbagai periode ulang. Dalam pemodelan kejadian banjir terdapat tiga komponen hidrologis utama yaitu kehilangan air (Losses), hidrograf satuan sintetik (Transform), dan aliran dasar (Baseflow). Dalam analisis kejadian banjir, komponen Losses dan Transform berupa hidrograf satuan sintetik menjadi komponen utama yang terpenting sedangkan komponen Baseflow memiliki pengaruh lebih kecil. Walaupun seperti itu ketiga komponen saling berinteraksi dalam menghasilkan hidrograf banjir. Pada Gambar 4 ditunjukkan pemodelan DAS Waduk Selorejo pada HEC-HMS.

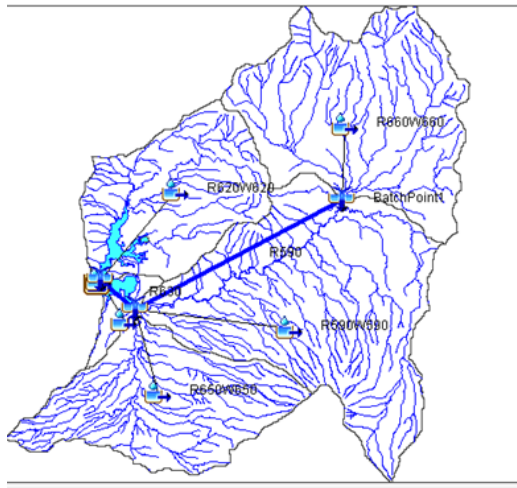

Gambar 4. Pemodelan HEC-HMS DAS Selorejo

Pada proses pemodelan ini, seluruh data kondisi fisik DAS Selorejo di input ke dalam pemodelan tersebut. Setelah itu nilai parameter dari tiga komponen hidrologis kehilangan air (Losses), hidrograf satuan sintetik (Transform), dan aliran dasar (Baseflow) dimasukkan. Berdasarakan penelitian sebelumnya pada DAS Selorejo, nilai ketiga komponen di atas sudah ada dan menunjukkan hasil yang cukup baik [8]. Berikut ditunjukkan nilai parameter dari masing-masing komponen dan hasil kalibrasi nya.

Tabel 1. Parameter Komponen Hidrologis DAS Waduk Selorejo [8]

\begin{tabular}{|c|c|c|c|c|c|c|c|}
\hline & & \multicolumn{6}{|c|}{ SCS Curve Number } \\
\hline & & $\begin{array}{c}R \\
590\end{array}$ & $\begin{array}{c}R \\
600\end{array}$ & $\begin{array}{c}R \\
620 \\
\end{array}$ & $\begin{array}{c}R \\
630 \\
\end{array}$ & $\begin{array}{c}\mathrm{R} \\
650\end{array}$ & $\begin{array}{c}R \\
660\end{array}$ \\
\hline \multirow[t]{4}{*}{$\begin{array}{c}\text { Dec- } \\
07\end{array}$} & $\begin{array}{l}\text { initial } \\
\text { abstract } \\
\text { ion } \\
(\mathrm{mm})\end{array}$ & \multicolumn{6}{|c|}{ Standard HEC-HMS (0.2 S) } \\
\hline & \multirow[t]{3}{*}{$\begin{array}{l}\text { Curve } \\
\text { Number }\end{array}$} & 56 & 87 & 56 & 61 & 49 & 46 \\
\hline & & & SCS & Unit H & ydrogr & aph & \\
\hline & & $\begin{array}{c}R \\
590 \\
\end{array}$ & $\begin{array}{c}R \\
600 \\
\end{array}$ & $\begin{array}{c}R \\
620 \\
\end{array}$ & $\begin{array}{c}R \\
630 \\
\end{array}$ & $\begin{array}{c}R \\
650 \\
\end{array}$ & $\begin{array}{c}R \\
660 \\
\end{array}$ \\
\hline \multirow{2}{*}{$\begin{array}{l}\text { Dec- } \\
07\end{array}$} & $\begin{array}{l}\text { Graph } \\
\text { Type (mm) }\end{array}$ & \multicolumn{6}{|c|}{ Standard (PRF 484) } \\
\hline & $\begin{array}{l}\text { Lag Time } \\
\text { (min) }\end{array}$ & 151.5 & 12 & 69.1 & 40.5 & 64.2 & 71.9 \\
\hline
\end{tabular}




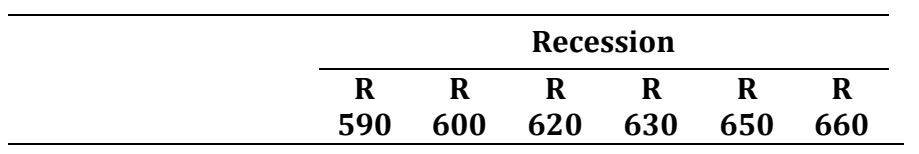

initial

$\begin{array}{lllllll}\text { discharge } & 0.01 & 0.01 & 0.01 & 0.01 & 0.01 & 0.01\end{array}$

(m3/s/km2)

\begin{tabular}{clllllll} 
Dec- & Recession & 0.9 & 0.9 & 0.9 & 0.9 & 0.9 & 0.9 \\
07 & Constant & & & & & & \\
\hline
\end{tabular}

$\begin{array}{llllllll}\text { Ratio } & \text { to } & 0.1 & 0.1 & 0.1 & 0.1 & 0.1 & 0.1 \\ \text { Peak } & & & & & \end{array}$

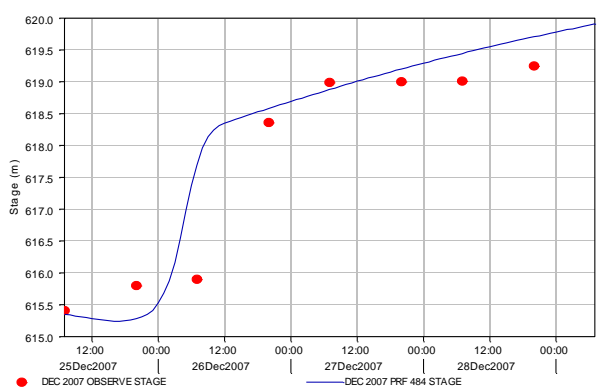

Gambar 5. Hasil Kalibrasi Model HEC-HMS DAS Waduk Selorejo [8]

Tabel 2. Nilai Fungsi Objektif Hasil Kalibrasi Model

\begin{tabular}{ll} 
& {$[8]$} \\
\hline & $\begin{array}{l}\text { Fungsi } \\
\text { Objektif }\end{array}$ \\
\hline $\begin{array}{l}\text { RMSE (m) } \\
\text { Correl }\end{array}$ & 0.7 \\
$\begin{array}{l}\text { Delta Peak } \\
(\%)\end{array}$ & 0.931 \\
\hline
\end{tabular}

Berdasarkan hasil kalibrasi yang ditujukkan pada Gambar 5 dan Tabel 2 dengan menggunakan parameter yang ditunjukkan pada Tabel 1, proses kalibrasi yang dilakukan sudah menunjukkan hasil yang baik. Pada Gambar 5 dapat dilihat berupa grafik yang menunjukkan elevasi tampungan hasil pemodelan dan hasil pengamatan nya, garis biru menunjukkan hasil pemodelan dan titik merah menunjukkan data pengamatan. Dari Gambar 5 ini dapat dilhat hasil pemodelan sudah mendekati hasil pengamatan. hal ini terbukti pula dengan nilai fungsi objektif yang ditunjukkan pada Tabel 2 memiliki nilai yang baik. Fungsi objektif Root Mean Square Error (RMSE) yang merepresentasikan nilai simpangan antara hasil kalibrasi dan pengamatan menunjukkan nilai yang kecil di bawah $1 \mathrm{~m}$ berarti simpangan nya kecil. Selain itu fungsi objektif Correl atau Coefficient Correlation yang merepresentasikan kecocokan antara dua set data yang dibandingkan yaitu hasil pemodelan dan pengamatan menunjukkan nilai mendekati 1 yang artinya dua set data memiliki kecocokan yang tinggi. Kemudian fungsi objektif Delta Peak atau beda puncak merepresentasikan perbedaan nilai puncak antara hasil pemodelan dan data pengamatan menunjukkan nilai lebih kecil dari $20 \%$ sehingga dapat dikatakan hasil pemodelan sudah cukup baik. Sehingga dapat disimpulkan setelah dilakukan proses kalibrasi, parameter pemodelan pada Tabel 1 menunjukkan hasil yang baik dan dapat digunakan untuk merepresentasikan kondisi banjir pada DAS Waduk Selorejo untuk Analisis Debit Banjir DAS Selorejo untuk berbagai periode ulang.

\section{Analisis Curah Hujan dan Debit Banjir Periode Ulang}

Dalam evaluasi tampungan waduk perlu dilakukan analisis curah hujan pada berbagai periode ulang. Tujuan dilakukan analisis karena sebuah waduk di desain dengan tujuan untuk menampung debit banjir sampai periode ulang tertentu. Oleh karena itu untuk mendapatkan nilai banjir periode ulang tersebut perlu dilakukan analisis perhitungan curah hujan periode ulang nya.

Menurut peraturan dan regulasi yang berlaku di Indonesia, perhitungan curah hujan periode ulang menggunakan 5 distribusi yaitu Distribusi Normal, Log Normal, Gumbel, Pearson III, dan Log Pearson III. [9]. Namun pada penelitian yang dilakukan di Wadi Byash DAM di Arab Saudi terdapat 1 distribusi lain yaitu Generalized Extreme Value (GEV) [6]. Berdasarkan penelitian tersebut, menunjukkan bahwa sebagian besar distribusi hujan yang cocok adalah distribusi GEV. Oleh karena itu pada penelitian ini selain dari 5 distribusi yang dianjurkan oleh SNI, distribusi GEV akan juga digunakan.

Pada bagian karakteristik DAS sempat disebutkan bahwa pada DAS Waduk Selorejo terdapat 4 pos hujan yaitu Jombok, Sekar, Selorejo dan Pujon. Untuk menentukan nilai hujan periode ulang diperlukan data hujan harian maksimum tahunan masing-masing pos hujan. Dari data yang diperoleh data hujan harian masing-masing pos hujan terdiri dari tahun 1990 sampai 2016. Berikut hujan harian maksimum tahunan untuk masing masing pos hujan.

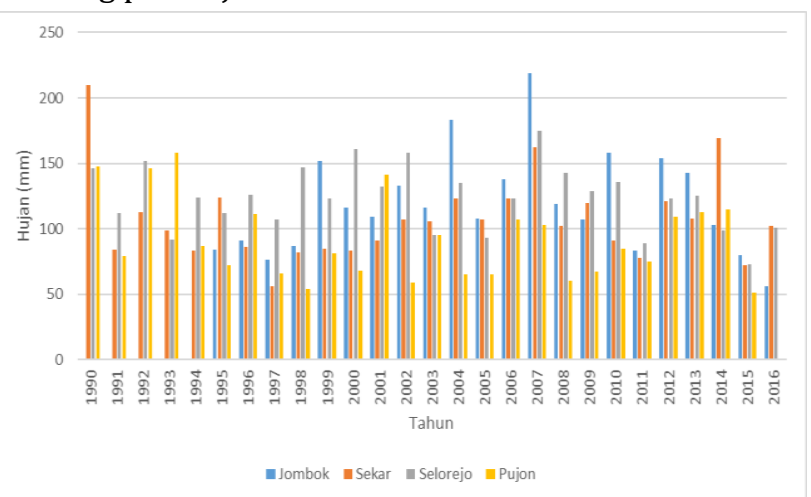

Gambar 6. Hujan Harian Maksimum

Tahunan Masing-masing Pos Hujan Pada DAS Waduk Selorejo 
Dengan data hujan harian maksimum yang ditunjukkan pada Gambar 6, dilakukan analisis frekuensi dengan 6 metode distribusi yang telah disebutkan sebelumnya untuk menentukan nilai hujan berbagai periode ulang. Berikut hasil analisis frekuensi pada pos hujan Selorejo.

Tabel 3. Hasil Analisis Frekuensi Hujan Pos Hujan Selorejo

\begin{tabular}{|c|c|c|c|c|c|c|c|}
\hline \multirow[b]{2}{*}{$\begin{array}{l}\text { Kala Ulang } \\
\text { (Tahun) }\end{array}$} & \multicolumn{7}{|c|}{ Distribusi Probabilitas } \\
\hline & $\begin{array}{l}\text { Nor } \\
\text { mal }\end{array}$ & $\begin{array}{l}\text { Lognor } \\
\text { mal 2 } \\
\text { Param } \\
\text { eter }\end{array}$ & $\begin{array}{l}\text { Lognor } \\
\text { mal } 3 \\
\text { Param } \\
\text { eter }\end{array}$ & $\begin{array}{l}\text { Gum } \\
\text { bel I }\end{array}$ & $\begin{array}{l}\text { Pear } \\
\text { son } \\
\text { III }\end{array}$ & $\begin{array}{l}\text { Log } \\
\text { Pear } \\
\text { son } \\
\text { III }\end{array}$ & GEV \\
\hline 2 & 123.4 & 120.9 & 123.3 & 119.6 & 123.3 & 122.7 & 123.2 \\
\hline 5 & 144.3 & 143 & 144.2 & 145.2 & 144.2 & 144.5 & 145.4 \\
\hline 10 & 155.2 & 156.1 & 155.2 & 162.1 & 155.2 & 156.1 & 156.6 \\
\hline 20 & 164.2 & 167.8 & 164.4 & 178.3 & 164.4 & 165.7 & 165.5 \\
\hline 25 & 166.8 & 171.4 & 167 & 183.5 & 167 & 168.5 & 167.9 \\
\hline 50 & 174.3 & 182.1 & 174.7 & 199.3 & 174.7 & 176.5 & 174.5 \\
\hline 100 & 181.1 & 192.2 & 181.6 & 215.1 & 181.6 & 183.6 & 180 \\
\hline 500 & 194.8 & 214.6 & 195.6 & 251.5 & 195.6 & 197.8 & 189.1 \\
\hline 1000 & 200.1 & 223.8 & 201 & 267.1 & 201 & 203.1 & 192 \\
\hline $\begin{array}{l}\begin{array}{c}\text { Penyimpan } \\
\text { gan } \\
\text { Maksimum }\end{array} \\
\end{array}$ & 6.63 & 6.94 & 6.61 & 8.65 & 6.7 & 6.2 & 5.57 \\
\hline $\begin{array}{c}\text { Delta Kritis } \\
\text { (Sig. Level } \\
5 \% \text { ) }\end{array}$ & 25.52 & 25.52 & 25.52 & 25.52 & 25.52 & 25.52 & 25.52 \\
\hline
\end{tabular}

Pada Tabel 3 terlihat hasil analisis frekuensi untuk berbagai macam periode ulang untuk masing-masing metode distribusi. Hasil menunjukkan bahwa setiap distribusi menunjukkan hasil yang baik dimana nilai penyimpangan maksimum untuk masing-masing distribusi lebih kecil dari nilai delta kritisnya. Namun untuk pemilihan distribusi yang terbaik dapat dilihat dari nilai penyimpangan maksimum terkecil dari seluruh distribusi. Berdasarkan hasil analisis yang ditunjukkan Tabel 3, pada Pos Hujan Selorejo nilai penyimpangan maksimum terkecil ditunjukkan olej distribusi GEV dengan nilai 5.57. Dari hasil analisis ini dapat disimpulkan bahwa untuk Pos Hujan Selorejo, metode distribusi terbaik ditunjukkan oleh distribusi GEV. Untuk rekapitulasi nilai analisis frekuensi dan metode terbaik pada seluruh pos hujan ditunjukkan pada Tabel 4. Selain hujan periode ulang, perlu pula ditentukan nilai hujan maksimum boleh jadi atau Probable Maximum Precipitation (PMP). Hal ini perlu dilakukan karena waduk besar di Indonesia menggunakan debit desain Probable Maximum Flood (PMF) yang merupakan hasil transformasi PMP sebagai desain tampungan waduk nya. [10] . Berdasarkan hal ini penentuan nilai PMP perlu dilakukan. Untuk menentukan nilai PMP digunakan metode Hersfield yang metode perhitungannya terdapat pada [11]. Rekapitulasi nilai PMP untuk masing-masing pos hujan tertera pula pada Tabel 4 .
Tabel 4. Rekapitulasi Hasil Analisis Frekuensi Hujan Pos Hujan DAS Waduk Selorejo

\begin{tabular}{|c|c|c|c|c|}
\hline \multirow[b]{2}{*}{$\begin{array}{l}\text { Periode } \\
\text { Ulang }\end{array}$} & \multicolumn{4}{|c|}{ Hujan Rencana } \\
\hline & $\begin{array}{c}\text { Selorejo } \\
\text { mm }\end{array}$ & $\begin{array}{c}\text { Jombok } \\
\text { mm }\end{array}$ & $\begin{array}{c}\text { Sekar } \\
\text { mm }\end{array}$ & $\begin{array}{c}\text { Pujon } \\
\text { mm }\end{array}$ \\
\hline 2 & 123.20 & 116.40 & 99.60 & 86.8 \\
\hline 5 & 145.40 & 155.50 & $\begin{array}{l}127.6 \\
0\end{array}$ & 119.1 \\
\hline 10 & 156.60 & 181.40 & $\begin{array}{l}148.4 \\
0\end{array}$ & 140.4 \\
\hline 20 & 165.50 & 206.20 & $\begin{array}{l}170.3 \\
0\end{array}$ & 160.9 \\
\hline 25 & 167.90 & 214.10 & $\begin{array}{l}177.7 \\
0\end{array}$ & 167.4 \\
\hline 50 & 174.50 & 238.30 & $\begin{array}{l}201.8 \\
0\end{array}$ & 187.4 \\
\hline 100 & 180.00 & 262.40 & $\begin{array}{l}228.0 \\
0\end{array}$ & 207.3 \\
\hline 500 & 189.10 & 318.10 & $\begin{array}{l}297.9 \\
0\end{array}$ & 253.2 \\
\hline 1000 & 192.00 & 342.00 & $\begin{array}{l}332.6 \\
0\end{array}$ & 272.9 \\
\hline PMP & 571.12 & 727.79 & $\begin{array}{l}629.9 \\
7 \\
\end{array}$ & 675.50 \\
\hline Distribusi & GEV & Gumbel I & GEV & Gumbel I \\
\hline
\end{tabular}

Hujan yang dihasilkan dari analisis frekuensi masih besifat hujan titik oleh karena itu perlu diubah menjadi hujan wilayah. Berdasarkan Poligon Thiessen yang terdapat pada Gambar 3, Hujan titik dapat diubah menjadi hujan wilayah. Nilai hujan wilayah untuk masing-masing subDAS Waduk Selorejo ditunjukkan pada Tabel 5. Walaupun sudah bersifat hujan wilayah nilai tersebut masih kurang presisi karena nilai tersebut masih terlalu besar oleh karena itu nilai hujan wilayah tersebut perlu dikalikan sebuah faktor reduksi yang disebut Areal Reduction Factor (ARF) sehingga nilai hujan wilayah menjadi lebih presisi. [12]. Persamaan ARF yang digunakan adalah persamaan Modified Bell dengan persamaan:

$A R F_{m}$

$=1$

$-0.4\left(A^{0.14}-0.7 \log T d\right) T d^{-0.48}$

$+0.002 A^{0.4} T d^{0.41}\left[0 .+\log \left(\frac{1}{T}\right)\right]$

Dimana:

$\mathrm{ARF}_{\mathrm{m}}$ = areal reduction factor;

A = daerah aliran ( $\mathrm{km} 2)$;

$\mathrm{T}=$ periode ulang (tahun);

$\mathrm{Td}=$ durasi badai (jam).

Rentang aplikasi:

$1 \mathrm{~km} 2 \leq \mathrm{A} \leq 10,000 \mathrm{~km} 2$

$\mathrm{T}=2$ tahun -200 tahun

18 jam $\leq \mathrm{Td} \leq 120$ jam

[Sumber:Pietersen et.al., 2017] 
Berdasarkan Persamaan 1, nilai ARF untuk masing-masing periode ulang dapat ditentukan. Nilai ARF untuk masing-masing periode ulang terdapat pada Tabel 6

Tabel 5. Curah Hujan Wilayah DAS Waduk Selorejo

\begin{tabular}{lllllll}
\hline \multirow{2}{*}{$\begin{array}{l}\text { Periode } \\
\text { Ulang }\end{array}$} & \multicolumn{6}{c}{ SubDAS } \\
\cline { 2 - 7 } & $\mathbf{R 5 9 0}$ & $\mathbf{R 6 0 0}$ & $\mathbf{R 6 2 0}$ & $\mathbf{R 6 3 0}$ & $\mathbf{R 6 5 0}$ & $\mathbf{R 6 6 0}$ \\
\hline 2 & 93.3 & 123.2 & 117.4 & 117.4 & 99.6 & 95.2 \\
5 & 123.8 & 145.4 & 141.1 & 141.1 & 127.6 & 129.4 \\
10 & 144.1 & 156.6 & 154.6 & 154.6 & 148.4 & 152.0 \\
20 & 163.8 & 165.5 & 166.7 & 166.7 & 170.3 & 173.7 \\
25 & 170.1 & 167.9 & 170.3 & 170.3 & 177.7 & 180.6 \\
50 & 189.8 & 174.5 & 181.2 & 181.2 & 201.8 & 201.8 \\
100 & 209.7 & 180.0 & 191.7 & 191.7 & 227.9 & 222.9 \\
500 & 257.3 & 189.1 & 215.7 & 215.7 & 297.7 & 271.6 \\
1000 & 278.7 & 192.0 & 226.3 & 226.3 & 332.4 & 292.5 \\
PMP & 656.4 & 571.1 & 585.5 & 585.5 & 629.9 & 690.3 \\
\hline
\end{tabular}

Tabel 6. ARF DAS Waduk Selorejo

\begin{tabular}{lr}
\hline $\begin{array}{c}\text { Periode } \\
\text { Ulang }\end{array}$ & ARF \\
\hline 2 & 0.8972 \\
5 & 0.8712 \\
10 & 0.8515 \\
20 & 0.8319 \\
25 & 0.8256 \\
50 & 0.8059 \\
$>100$ & 0.7862 \\
\hline
\end{tabular}

Sebelum proses Analisis debit banjir pada DAS Waduk Selorejo dilakukan, data hujan periode ulang perlu didistribusi secara jam-jam an. Hal ini dilakukan karena data hujan jam-jam an yang dimiliki hanya terdapat pada pos hujan Selorejo dan Pujon sedangkan pada pos hujan Jombok dan Sekar tidak tersedia. Akibat keterbatasan ini, data hujan hasil analisis frekuensi perlu didistribusikan jam-jam an nya berdasarkan beberapa distribusi. Pemilihan distribusi yang terbaik akan berdasarkan kecocokannya dengan data hujan jamjam an yang terdapat pada pos hujan Selorejo dan Pujon.

Berdasarkan penelitian sebelumnya pada DAS Cikapundung Hulu, Minahasa dan Jakarta, terdapat beberapa metode distribusi hujan jamjam an yang digunakan yaitu Distribusi Huff, PSA 005, dan SCS. [13] [14] [15]. Berikut hasil analisis distribusi hujan jam-jam an pada pos hujan DAS Waduk Selorejo.

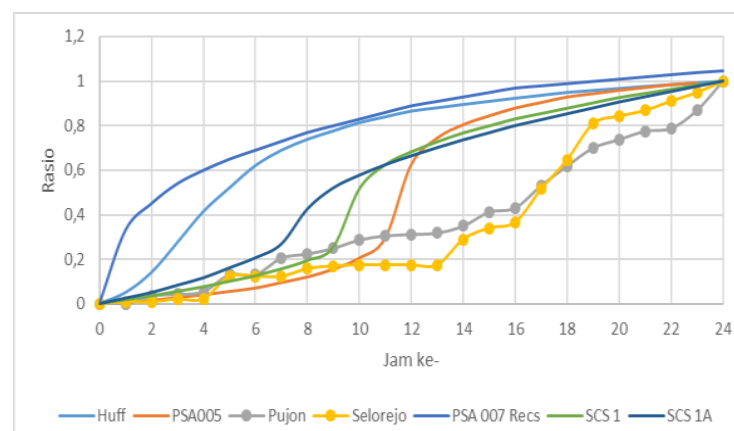

Gambar 7. Distribusi Hujan jam-jam an Pos Hujan di DAS Waduk Selorejo

Gambar 7 menunjukkan hasil analisis distribusi hujan jam-jam an pada pos hujan Selorejo dan Pujon terhadap beberapa metode distribusi hujan. Dapat terlihat bahwa distribusi hujan yang paling mendekati distribusi hujan jamjam an pos hujan Selorejo dan Pujon adalah Distribusi PSA 005. Oleh karena itu untuk analisis debit banjir DAS Waduk Selorejo digunakan distribusi PSA 005. Distribusi hujan jam-jam an diperlukan untuk memodelkan bobot hujan jamjam an pada kejadian hujan periode ulang yang telah di analisis pada bagian sebelumnya.

Setelah seluruh proses pengolahan dan analisis data yang dilakukan pada bagian sebelumnya, proses analisis debit banjir dari DAS Waduk Selorejo dapat dilakukan. Dengan konfigurasi model DAS Waduk Selorejo yang ditunjukkan pada Gambar 4, Parameter hidrologis pada Tabel 1, nilai hujan periode ulang pada Tabel 5 , nilai ARF pada Tabel 6 dan distribusi hujan jam-jam menggunakan metode PSA 005 dapat diperoleh debit banjir periode ulang DAS Waduk Selorejo. Dengan nilai debit banjir periode ulang DAS Waduk Selorejo telah diketahui evaluasi tampungan Waduk Selorejo dapat dilakukan. Berikut adalah rekapitulasi hasil analisis debit banjir DAS Waduk Selorejo.

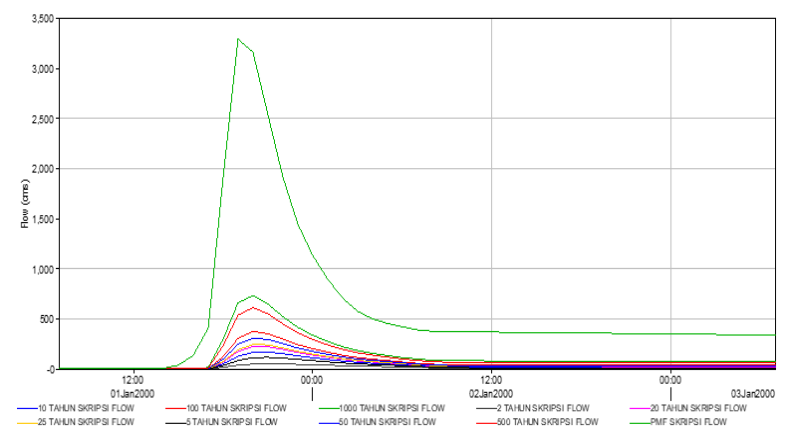

Gambar 8. Hasil Analisis Debit Banjir DAS Waduk Selorejo 
Tabel 7. Debit Puncak Hasil Analisis Debit Banjir

\begin{tabular}{ll}
$\begin{array}{c}\text { Periode } \\
\text { Ulang }\end{array}$ & $\begin{array}{c}\text { Debit } \\
\text { Puncak } \\
\text { (m³ } \mathbf{3} \text { ) }\end{array}$ \\
\hline 2 & 50.231 \\
5 & 114.03 \\
10 & 168.58 \\
20 & 227.31 \\
25 & 246.95 \\
50 & 309.61 \\
100 & 375.23 \\
500 & 615.04 \\
1000 & 734.54 \\
PMF & $3,158.20$ \\
\hline
\end{tabular}

Pada Gambar 8 dan Tabel 7 menunjukkan hasil debit banjir yang akan ditampung Waduk Selorejo, nilai ini diperoleh dari mengkombinasikan seluruh hasil analisis yang telah dilakukan sebelumnya, yaitu parameter pemodelan hasil kalibrasi, hasil hujan periode ulang yang ditunjukkan pada Tabel 5, nilai ARF pada Tabel 6, serta distribusi hujan jam-jam an yang ditunjukkan oleh Gambar 7. Besar debit banjir yang ditunjukkan oleh Tabel 7 ini digunakan untuk proses penelusuran banjir tampungan Waduk Selorejo, guna mengetahui elevasi Waduk Selorejo pada kondisi banjir berbagai periode ulang. Hasil penelusuran banjir ini akan menunjukkan apakah Waduk Selorejo masih mampu untuk menampung banjir tersebut dan berfungsi sesuai desain awal nya.

\section{Evaluasi Tampungan Waduk Selorejo}

Berdasarkan hasil analisis debit banjir yang telah dilakukan pada bagian sebelumnya, evaluasi tampungan Waduk Selorejo dapat dilakukan. Evaluasi tampungan yang dilakukan untuk melihat potensi Overtopping dari Waduk Selorejo akibat adanya pengurangan volume tampungan Waduk Selorejo. Berikut adalah grafik elevasi-volume dari Waduk Selorejo.

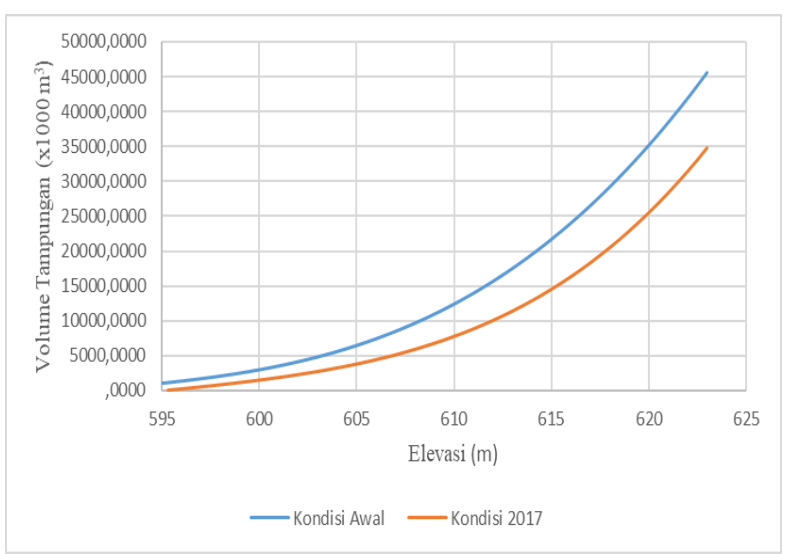

Gambar 9. Grafik Elevasi Tampungan Waduk Selorejo
Pada Gambar 9 terlihat bahwa tampungan Waduk Selorejo mengalami penurunan volume tampungan. Hal ini diakibatkan adanya akumulasi endapan sedimen yang terbawa oleh aliran sungai yang masuk menuju Waduk Selorejo. Evaluasi kinerja tampungan Waduk Selorejo dilakukan pada kondisi tahun 2017 apakah dengan volume tampungan pada kondisi tersebut masih mampu melaksanakan fungsinya untuk pengendalian banjir. Berdasarkan hasil pemodelan menggunakan HEC-HMS, kinerja tampungan Waduk Selorejo ditunjukkan oleh grafik berikut.

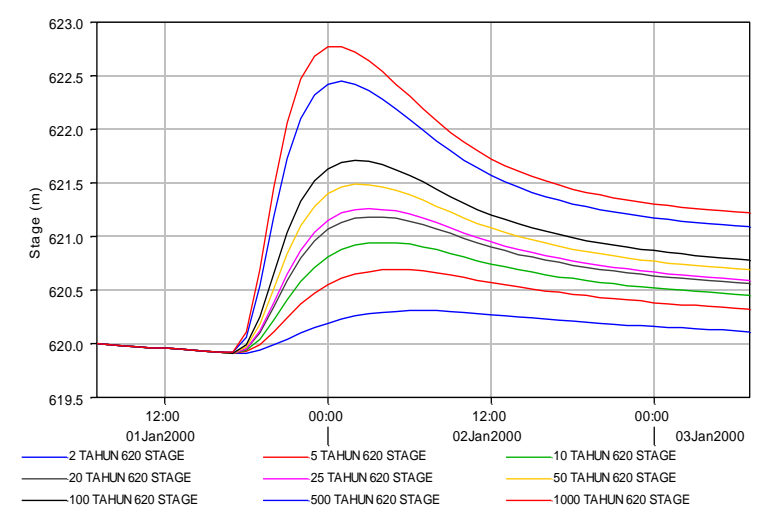

Gambar 10. Hasil Evaluasi Tampungan Waduk Selorejo

Pada Gambar 10 ditunjukkan hasil evaluasi tampungan Waduk Selorejo. Berdasarkan dokumen Operasi dan Pemeliharaan Waduk Selorejo, Elevasi tertinggi Waduk Selorejo berada di +625 m. Gambar 10 menunjukkan elevasi tertinggi masing-masing periode ulang masih berada di bawah $+625 \mathrm{~m}$. Dokumen Operasi dan Pemeliharaan Waduk Selorejo juga menambahkan bahwa Waduk Selorejo dibangun dengan desain debit periode ulang 1000 Tahun. Melihat fakta ini, elevasi maksimum akibat banjir periode ulang 1000 tahun adalah $+622,68 \mathrm{~m}$ masih berada di bawah elevasi puncak Waduk Selorejo yaitu +625 $\mathrm{m}$. Sehingga dapat disimpulkan bahwa tampungan Waduk Selorejo masih mampu untuk menerima banjir dengan periode ulang pada tahap awal desain dan pembangunannya. Walaupun seperti itu tampungan Waduk Selorejo perlu juga di cek terhadap debit PMF nya agar keamanan Waduk Selorejo lebih terjamin. Berdasarkan analisis yang dilakukan, elevasi puncak Waduk Selorejo akibat debit PMF +627,29 m berada di atas elevasi puncak Waduk Selorejo di +625 m. hal ini menunjukkan bahwa dalam keadaan normal Waduk Selorejo tidak mampu menampung debit banjir PMF. Oleh karena itu dilakukan beberapa alternatif cara agar Waduk Selorejo mampu menampung debit PMF. Alternatif yang dilakukan adalah dengan menurunkan muka air awal di Waduk Selorejo. Pada kondisi normal, muka air waduk ditahan pada elevasi $+620 \mathrm{~m}$ namun melihat pada kondisi normal Waduk Selorejo tidak mampu menampung debit PMF maka muka air diturunkan pada 
beberapa elevasi. Berikut adalah hasil analisis penelusuran muka air Waduk Selorejo pada berbagai kondisi muka air awal.

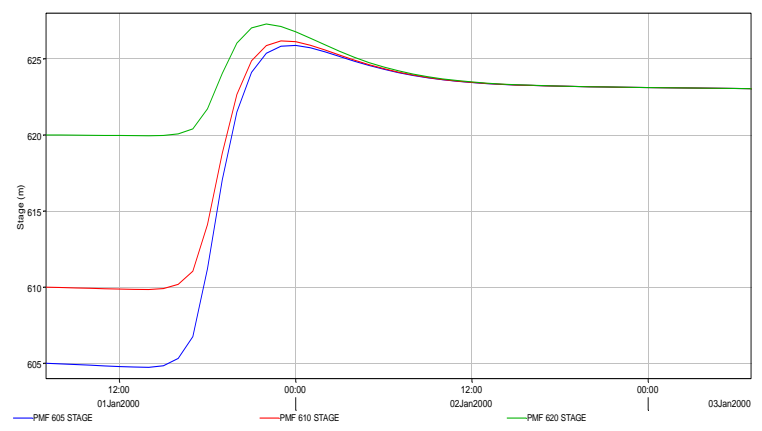

Gambar 11. Grafik Elevasi Tampungan Waduk Selorejo Kondisi PMF

Tabel 8. Elevasi Puncak Tampungan Waduk Selorejo Kondisi PMF

\begin{tabular}{cc}
$\begin{array}{c}\text { Elevasi } \\
\text { Awal } \\
\text { (m) }\end{array}$ & $\begin{array}{c}\text { Elevasi } \\
\text { Puncak } \\
\text { (m) }\end{array}$ \\
\hline 620 & 627.29 \\
610 & 626.17 \\
605 & 625.88 \\
\hline
\end{tabular}

Dari hasil yang ditunjukkan oleh Gambar 11 dan Tabel 8, solusi pengendalian banjir PMF pada Waduk Selorejo dapat dilakukan dengan menurunkan muka air awal Waduk Selorejo. Namun dapat dilihat walaupun menurunkan muka air awal Waduk Selorejo sampai elevasi +605 m, muka air puncak di Waduk Selorejo berada di elevasi $+625,88 \mathrm{~mm}$ berada di atas puncak Waduk Selorejo di +625 m. Berdasarkan observasi lapangan dan pengumpulan data disebutkan bahwa di atas elevasi +625 m, Waduk Selorejo masih memiliki parapet setinggi 1 meter. Sehingga dapat disimpulkan bahwa Waduk Selorejo masih mampu untuk menampung banjir sampai elevasi +626 m. Hal ini berarti dengan menurunkan muka air awal Waduk Selorejo sampai ke elevasi +605 m, Waduk Selorejo mampu untuk menampun debit banjir PMF.

\section{KESIMPULAN}

Dari proses analisis yang telah dilakukan dapat disimpulkan bahwa Waduk Selorejo masih mampu berfungsi sesuai desain awal nya yatu mampu menahan banjir periode ulang 1000 Tahun dengan besar debit banjir $735.54 \mathrm{~m}^{3}$ dan elevasi tampungan di $622.28 \mathrm{~m}$. Selain hal tesebut dilakukan pengujian apakah Waduk Selorejo aman terhadap banjir PMF dimana hasil menunjukkan dengan kondisi muka air $+620 \mathrm{~m}$, elevasi Waduk Selorejo berada di atas puncak tertingginya sehingga perlu dilakukan proses pengendalian banjir. Hasil analisis menunjukkan bahwa dengan menunrunkan muka air awal Waduk Selorejo sampai +605 m, muka air maksimum Waduk Selorejo akibat banjir PMF menjadi +625.88 $\mathrm{m}$ yang artinya Waduk Selorejo mampu untuk menampung banjir PMF.

\section{REFERENSI}

[1] M. T. Abror, R. Setiawan, S. Darsono, and H. Nugroho, "Perancangan Waduk Mundingan di Kota Semarang," vol. 4, no. 4, pp. 406-414, 2015, [Online]. Available: http://ejournals1.undip.ac.id/index.php/jkts.

[2] M. A. Sudarmin, "Analisis Banjir Rancangan dan Kapasitas Pelimpah Bendungan Way Yori."

[3] Khoiriyah, "Evaluasi Keamanan Bendungan Waduk Cengklik Periode Ulang 1000 Tahun."

[4] M. Imamuddin, "Evaluasi Kapasitas Tampungan Setu Tarisi Kabupaten Majalengka," 2016.

[5] T. Tingsanchali and S. Tanmanee, "Assessment of hydrological safety of Mae Sruai Dam, Thailand," in Procedia Engineering, 2012, vol. 32, pp. 1198-1204, doi: 10.1016/j.proeng.2012.02.077.

[6] M. M. Abu-Abdullah, A. M. Youssef, N. H. Maerz, E. Abu-Alfadail, H. M. Al-Harbi, and N. S. AlSaadi, "A flood risk management program of wadi baysh dam on the downstream area: An integration of hydrologic and hydraulic models, Jizan region, KSA," Sustainability (Switzerland), vol. 12, no. 3, Feb. 2020, doi: $10.3390 /$ su12031069.

[7] Perusahaan Umum Jasa Tirta I, OPSLREJO.

[8] C. Cahyono and W. K. Adidarma, "Influence analysis of peak rate factor in the flood events' calibration process using HEC-HMS," Modeling Earth Systems and Environment, vol. 5, no. 4, pp. 1705-1722, Dec. 2019, doi: 10.1007/s40808-019-00625-8.

[9] Badan Standardisasi Nasional, SNI 2415: 2016 Tata Cara Perhitungan Debit Banjir Rencana. 2016.

[10] Pusat Penelitian dan Pengembangan Pengairan, "Bendungan Besar di Indonesia." 1995

[11] Badan Standardisasi Nasional, SNI-7746:2012. Tata Cara Perhitungan Perhitungan Hujan Maksimum Boleh Jadi dengan Metode Hershfield. 2012.

[12] J. P. J. Pietersen, J. O. Gericke, J. C. Smithers, and Y. E. Woyessa, "Review of current methods for estimating areal reduction factors applied to South African design point rainfall and preliminary identification of new methods," Journal of the South African Institution of Civil Engineering, vol. 57, no. 1, pp. 16-30, Mar. 
2015, $\quad$ doi: $\quad 10.17159 / 2309-$

8775/2015/v57n1a2.

[13] K. Christian, D. Yudianto, and S. R. Rusli, "Analisis Pola Distribusi Hujan Terhadap Perhitungan Debit Banjir Das Cikapundung Hulu," Jurnal Teknik Sumber Daya Air, vol. 3, no. 3, pp. 153-160, 2017.

[14] Ginting S., "Karakteristik Hujan Ekstrim Untuk Prediksi Debit Banjir di Jakarta," 2017.

[15] J. Swingly and F. Sumarauw, "Pola Distribusi Hujan Jam-Jaman Daerah Minahasa Selatan dan Tenggara," Jurnal Sipil Statik, vol. 4, no. 11, pp. 675-686, 2016.

\section{NOMENKLATUR}

PMF Probable Maximum Flood atau Banjir Maksimum Boleh Jadi

DAS Daerah Aliran Sungai

RMSE Root Mean Square Error

Correl Coefficient Correlation

GEV Generalized Extreme Value

PMP Probable Maximun Precipitation

ARF Areal Reduction Factor 
This page is intentionally blank 